\title{
Recognition of stressors in postgraduate students of a teaching University in Pakistan
}

\author{
Darayus P.Gazder ${ }^{1}$, Annie Adnan Ali ${ }^{1}$, Durre Fatima Naqvi ${ }^{1}$, Nosheen Zehra ${ }^{2}$, Irum Memon ${ }^{1}$, \\ Abdul Rafay ${ }^{1}$ \\ ${ }^{1}$ Medical Students, ${ }^{2}$ Department of Community Health Sciences, Ziauddin University, Karachi, Pakistan.
}

$\begin{array}{ll}\text { ARTICLE INFO } \\ \text { Received } & : 16 / 06 / 2014 \\ \text { Accepted } & : 03 / 11 / 2014 \\ \text { Published } & : 01 / 12 / 2014\end{array}$

\section{KEYWORD}

Postgraduate students

Stressors

Academic medicine

Clinical medicine

\section{ABSTRACT}

Objective: To recognize postgraduate stressors and their intensity among doctors doing post-graduation in the fields of academic and clinical medicine, using the Postgraduate Stressor Questionnaire (PSQ). Methods: A cross sectional study was conducted where the target population were postgraduate students. The PSQ was administered, a twenty-eight item questionnaire to identify and measure intensities of stressors. Questionnaires were administered to ninety post-graduate students, forty-five from each field. Data was entered on SPSS version 20. After descriptive analysis and checking the data for normality independent sample t-test and ANOVA were applied for numerical data, and chi square was applied for categorical data. Results: The mean age of the students was 30.97 (SD=6.52) years. Majority of the students were females. It was seen that academic related stressors were greatest among the two fields of medicine. Higher levels of stress were seen in students who were training in clinical medicine (mean=13.30, SD=4.84) than academic medicine (mean=12.27, SD=5.47). Conclusion: Postgraduate medical training is a highly stressful environment encountered by students. Academic related stressors were found to have its greatest impact in both the fields of medicine; this stress arises from scholastic, academic or educational events. Highest amounts of stress were seen in students enrolled in clinical medicine.

(c) Medical Education Department, School of Medical Sciences, Universiti Sains Malaysia. All rights reserved.

CORRESPONDING AUTHOR: Darayus P.Gazder, Medical Students, Department of Community Health Sciences, Ziauddin University, Karachi, Pakistan. Email: darayusthegreat@gmail.com

\section{Introduction}

Stress can be defined as "A psychological condition or emotional strain or suspense" [1]. Stress can occur in two dimensions it may have a positive or negative impact. When stress leads to a positive track it enhances performance, gives confidence and gives excellent end results. But when stress moves in a negative direction, it can cause physical and psychological destruction [2].
Pakistan's society is a conservative one, the society gives great respect and admiration to doctors and hence the medical profession is looked upon with awe in our society. Doctors are looked upon as "Healers." There is a lot of competition to enter medical school and the transition from school/college to a medical university is a big jump. Therefore, the struggle to enter a medical school, he/she has an enormous amount of complex materials to learn and they face competition against other brighter 
students. The duration of medical education and training is also a factor that contributes to stress in medical trainees. Medical school training in Pakistan is relatively long. It requires 5 years of schooling after completing 12 years of secondary and 1 year of house job [3]. Stress and emotional disturbances among students are relatively common, and seemingly, this is a worldwide problem [4]. Studies indicate that specific stress factors related to medical school may induce mental health problems, and a decrease in life satisfaction among students [5]. Distress may affect their performance as students and later as a caregiver for patients [6]. Bridging the gap between graduation from medical school and being board eligible in a medical specialty is a lengthy and arduous process.

Postgraduate medical training has always been regarded as a highly stressful environment to students [7]. Stress is a factor that generally results in negative thoughts and perceptions that, in turn, may adversely affect the performance of an individual [8].

Medical students after graduation pursue their career in either Academic (MPhil/PhD) or Clinical (Physician) medicine. High levels of stress are augmented once they enter into different programs. There may be intense competition in the selection of a field of their choice, associated with long working hours [8-9]. This could affect the overall performance of the individual and that in turn may lead to a cascade of events at both personal and professional levels [10].

Personal and environmental events that cause stress are known as stressors [11]. Sources of stress among postgraduate generally can be grouped into seven groups: academic, poor relationship with superiors, bureaucratic constraints, work-family conflicts, poor relationship with colleagues, performance pressure and poor job prospects related stressors [12].

Sources of stress among undergraduate medical students are well established in Pakistan [13-14]. However, for postgraduate medical trainees the available data is scarce particularly in Pakistan. Thus, the purpose of this study is to try and evaluate different stressors affecting postgraduate students and which stressor group has its maximum effect and intensity on students in different fields of post-graduation in medicine.

\section{Method}

A cross sectional study was conducted on postgraduate medical students studying and working in Ziauddin University. It was a one year project. A total of 90 postgraduate medical students were chosen and divided into two groups with forty-five students from each program of academic and clinical medicine respectively. Simple random sampling technique was employed for collection of data. The nature of survey, applicability of results and confidentiality were explained to the participants. Completion of questionnaire was voluntary and affirmed that it would not affect the progression of their course. The questionnaire was self-administered. The students were informed to follow the instructions. Filling of questionnaires took approximately 15 minutes and students were advised to return it on the same day. The questionnaire contained questions which were likert-type responses, multiple choice questions and open ended questions were filled by the students. Clearance was taken from the ethical review board prior to the start of study. The study was done with the perusal of the head of the institution and then informed consent was taken from participants.

Data was collected using a questionnaire consisting of two parts: (i) socio-demographic questions and (ii) questions designed to elicit information about the sources and levels of stress.

\section{Postgraduate Stressors Questionnaire (PSQ)}

This section dealt with seven stressors affecting students, it was a 28 item questionnaire [15]. The seven stressors analyzed were Academic related stressors (ARS), Poor relationship with superior related stressors (PRRS), Bureaucratic 
constraints related stressors (BCRS), Workfamily conflicts related stressors (WFRS), Poor relationship with colleagues related stressors (PCRS), Performance pressure related stressors (PPRS), Poor Job prospects related stressors (PJRS).

The Postgraduate stressor questionnaire was developed to identify the stressors affecting postgraduate students as well as measure the intensity of stress caused by the stressors.

The reliability analysis showed that the Cronbach's alpha value for the PSQ was 0.95. Whereas, the Cronbach's alpha values for academic, poor relationship with superior, bureaucratic constraints, work-family conflicts, poor relationship with colleagues, performance pressure, and poor job prospect domains were $0.63,0.84,0.81,0.65,0.73,0.78$, and 0.70 respectively. For each potential stressor 5 categories were placed and classified as causing no stress at all, causing mild stress, causing moderate stress, causing high stress, causing severe stress to indicate intensity of stress caused by these items. Recommended scoring method of zero for least intensity of stress versus maximum of four for most intensity of stress was used that is scale of $0,1,2,3$, 4 was utilized as has been done by previous studies. Ethical consent was taken from the students before administration. Data was entered on SPSS version 20. Mean and standard deviation was taken out for stressor scores. $\mathrm{P}$ value less than 0.05 were taken as significant.

\section{Demographic Profile}

Ninety postgraduate medical students participated in this study, consisting of forty-five students from Academic (MPhil/PhD) and Clinical (Medicine/Surgery) programs. The demographic profile of the overall sample is shown in Table 1 . About $67.8 \%$ of the medical trainees were females, as $32.2 \%$ were male. $51.1 \%$ of the trainees were married, $46.7 \%$ were single and $2.2 \%$ were divorced. Mean age of the students was 30.97 and standard deviation 6.52. Eighty-one of the postgraduate students were working as paid employees, as the other 9 were working voluntarily with no profit. It was also seen that while $66.7 \%$ of students pursuing academic medicine work an average of 5 to 10 hours per day, as for $48.9 \%$ of students pursuing clinical medicine maintain similar average working hours. On the other hand, it was found that $31.1 \%$ of students pursuing clinical medicine actually work an average of 15 to 20 hours per day, while only $2.2 \%$ of students pursuing academic medicine maintain such lengthy average working hours (Figure 1).

Table 1: Demographic Conclusion

\begin{tabular}{lccc}
\hline Program & \multicolumn{2}{c}{$\begin{array}{c}\text { Postgraduate Students, } \mathbf{n} \\
\text { Male }\end{array}$} & Total \\
& Female & \\
\hline Academic & 14 & 31 & 45 \\
Clinical & 15 & 30 & 45 \\
& & & $\mathbf{9 0}$ \\
\hline
\end{tabular}

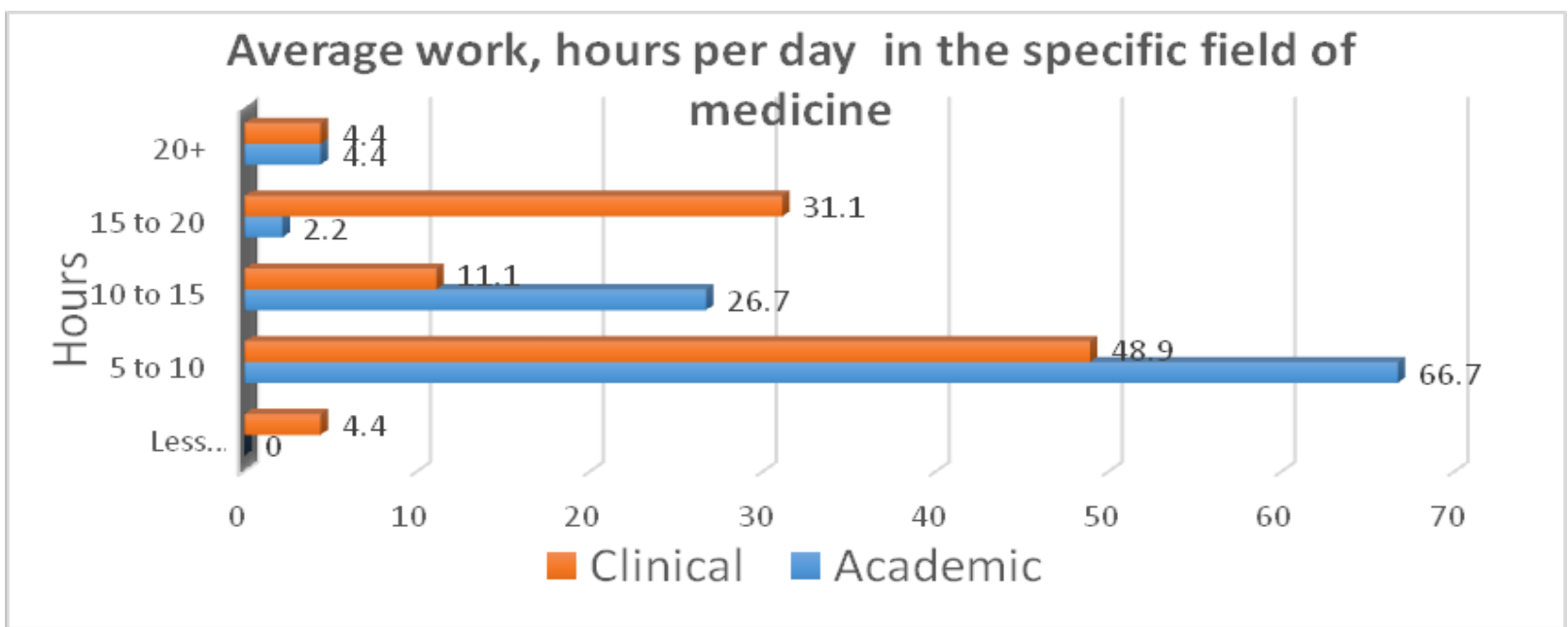

Figure 1: Percentage of work done by postgraduate students, in hours per day 


\section{Result}

Based on our study and observation of postgraduate medical training it was found to be a highly strenuous environment to students. All 7 of the stressors were found to directly impact the students. Lists of all the stressors are given in Tables 2 and 3 . The intensity of stress is diagrammatically represented on a bar graph (Figure 2) respectively. Results show that academic related stressors were the primary stressor affecting postgraduate medical students whose mean falls at 2.14. This stress arises from scholastic, academic or educational events. Performance pressure related stressors were the next major stressor and stands at a mean of 2.08it means that postgraduate students have a short duration given to complete high risk tasks where any mistake can lead to disastrous consequences and are generally burdened by work. This was followed by work family related stressors at a mean of 1.93. It can be described as stress arising when one's life is centred on work events leading to misery and distress feelings.

Table 2: Manifestation of stress among postgraduate students

\begin{tabular}{|c|c|c|}
\hline Stressor Group & Mean & $\begin{array}{l}\text { Standard } \\
\text { deviation }\end{array}$ \\
\hline ACADEMIC RELATED STRESSORS & 2.14 & \\
\hline Tests/Examinations & 2.42 & 0.99 \\
\hline Lack of time to review what has been learnt & 2.37 & 1.02 \\
\hline Difficulty understanding content & 1.50 & 1.01 \\
\hline Large amount of content to be learned & 2.26 & 0.99 \\
\hline PERFORMANCE PRESSURE RELATED STRESSORS & 2.08 & \\
\hline Time pressures and deadlines to meet & 2.07 & 0.97 \\
\hline Work overload & 2.24 & 1.15 \\
\hline Fear of making serious mistakes & 1.93 & 1.24 \\
\hline My work is mentally straining & 2.09 & 1.17 \\
\hline WORK FAMILY RELATED STRESSORS & 1.93 & \\
\hline Work demands affect by personal life & 2.29 & 1.27 \\
\hline Advancing a career at the expense of home life & 2.23 & 1.25 \\
\hline My life is too centered on my work & 1.81 & 1.26 \\
\hline Absence of emotional support from family & 1.37 & 1.26 \\
\hline BUREAUCRATIC CONSTRAINTS RELATED STRESSORS & 1.82 & \\
\hline Lack of authority to carry out my job duties & 1.83 & 1.27 \\
\hline Unable to make full use of my skills and ability & 1.99 & 1.27 \\
\hline Cannot participate in decision making & 1.73 & 1.30 \\
\hline Having to do work outside of my competence & 1.73 & 1.29 \\
\hline POOR RELATIONSHIP WITH SUPERIOR RELATED STRESSORS & 1.67 & \\
\hline Lack of support from superiors & 1.88 & 1.28 \\
\hline Difficulty in maintaining relationship with superior & 1.60 & 1.28 \\
\hline My beliefs contradict with those of my superior & 1.42 & 1.14 \\
\hline Unfair assessment from superiors & 1.78 & 1.32 \\
\hline POOR RELATIONSHIP WITH COLLEAGUES RELATED STRESSORS & 1.56 & \\
\hline Working with uncooperative colleagues & 1.80 & 1.24 \\
\hline Working with incompetence of colleagues & 1.71 & 1.14 \\
\hline Relationship problems with colleagues & 1.46 & 1.18 \\
\hline Competition among colleagues & 1.29 & 0.95 \\
\hline POOR JOB PROSPECTS RELATED STRESSORS & 1.56 & \\
\hline Feeling insecure in my job & 1.18 & 1.22 \\
\hline Society does not think highly of my profession & 1.10 & 1.31 \\
\hline Lack of promotion prospects & 1.74 & 1.34 \\
\hline Feeling of being underpaid & 2.20 & 1.47 \\
\hline
\end{tabular}


Table 3: Stressors in academic and clinical programs affecting postgraduate students

\begin{tabular}{lccc}
\hline Stressor & Academic, mean \pm SD & Clinical, mean \pm SD & Overall stress, mean \pm SD \\
\hline ARS & $2.10 \pm 0.797$ & $2.17 \pm 0.72$ & $2.14 \pm 0.76$ \\
PRRS & $1.52 \pm 1.10$ & $1.82 \pm 0.93$ & $1.67 \pm 1.02$ \\
BCRS & $1.72 \pm 1.11$ & $1.92 \pm 1.00$ & $1.82 \pm 1.05$ \\
WFRS & $1.97 \pm 1.14$ & $1.88 \pm 0.84$ & $1.93 \pm 1.00$ \\
PCRS & $1.37 \pm 0.92$ & $1.76 \pm 0.84$ & $1.56 \pm 0.90$ \\
PPRS & $2.08 \pm 0.96$ & $2.09 \pm 0.78$ & $2.08 \pm 0.87$ \\
PJRS & $1.51 \pm 1.02$ & $1.61 \pm 1.07$ & $1.56 \pm 1.04$ \\
\hline
\end{tabular}

Academic related stressors (ARS), Poor relationship with superior related stressors (PRRS), Bureaucratic constraints related stressors (BCRS), Work-family conflicts related stressors (WFRS), Poor relationship with colleagues related stressors (PCRS), Performance pressure related stressors (PPRS), Poor job prospects related stressors (PJRS).

$\mathrm{SD}=$ Standard Deviation

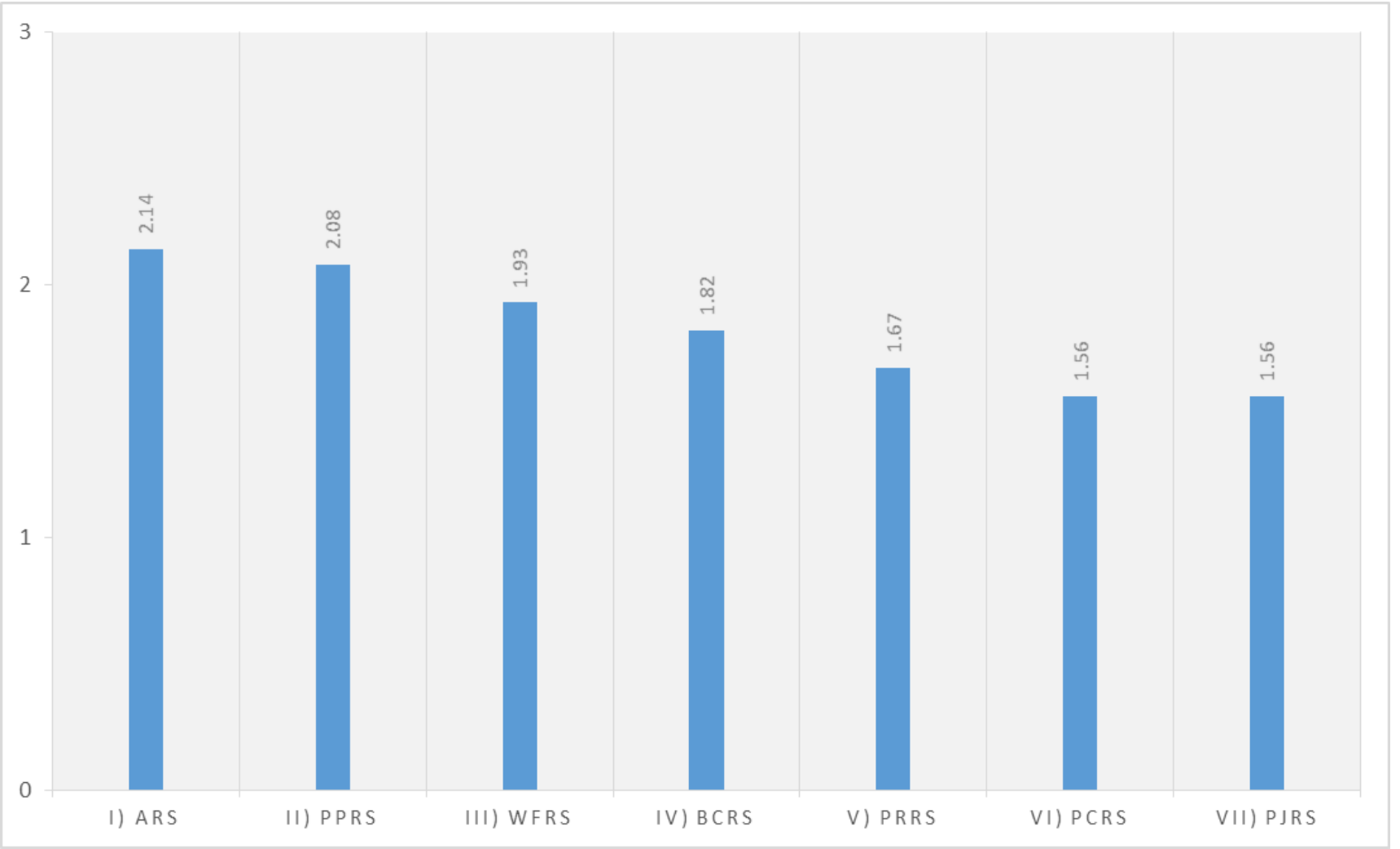

Figure 2: Overall Stressors (Bar chart)

\section{KEY:*}

$\mathrm{I}=$ Academic related stressors (ARS), II = Performance pressure related stressors (PPRS), III = Work-family conflicts related stressors (WFRS), IV = Bureaucratic constraints related stressors (BCRS), V = Poor relationship with superior related stressors (PRRS), ), VI = Poor relationship with colleagues related stressors (PCRS), VII = Poor Job prospects related stressors (PJRS). 
To measure the intensity of stress among the two groups. Mean and standard deviation were calculated of the stressors; as they are events that cause stress. Highest amounts of stress were attributed in postgraduate students who had enrolled in clinical programs, followed by the academic program. (Shown in Table 4)

Table 4. Levels of stress in the three programs calculated by stressors

\begin{tabular}{lccc}
\hline Program & N & Mean & $\begin{array}{c}\text { Standard } \\
\text { deviation }\end{array}$ \\
\hline Academic & 45 & 12.27 & 5.47 \\
Clinical & 45 & 13.30 & 4.84 \\
\hline
\end{tabular}

\section{Discussion}

Stress amongst postgraduate students is a wellknown fact. Postgraduate trainee doctors are receiving increasing attention, as it is perceived that excessive levels of stress may cause dissatisfaction, low morale and poor work performance [16]. It is known that doctors do suffer from high levels of psychological disturbance. The level of reported minor psychiatric morbidity ranges from approximately one-third for medical students and postgraduate trainee doctors entering their training programs, to over half for doctors who have become medical consultants and general practitioners [17-21].

The results of our study confirmed the observations of others as it indicated that postgraduate students are under considerable stress. Firth (1986) noticed that medical residents had higher stress levels than other groups in the general population in the UK [22]. It was also seen that postgraduate students who were enrolled in clinical medicine experienced higher levels of stress than acceptable, (Table 4) than students who took academic medicine. This maybe because of the long working hours, demanding schedules, night duties compounded by exposure to different patients.

Our results suggested that major stressors affecting postgraduate students were due to academic and performance related pressures also seen in a previous study [14]. An alarming number of postgraduate students are depressed due to lack of time in reviewing what has been learnt, and application of knowledge in tests and examinations. In the US, Collier et al (2002) noted an alarming number of postgraduate trainees who were depressed and showed increased level of cynicism and decreased levels of humanism. The authors attributed this to increases in their educational debts [23]. Similar observations were made in Canada [24-25].

Postgraduate medical training is extremely taxing on the students, both mentally and physically. This result is consistent with previous research, that postgraduate student's performance is affected by mentally straining work which they experience [26]. Work overload and pressure to complete given tasks, mostly within tight timelines contribute to high levels of stress. Bansal et al (2010) stated that $66.7 \%$ of the postgraduate students felt that high levels of stress were contributed due to work overload [27]. Stress due to work demands cause emotional disturbances to a person, this is attributed by work overload, short duration given to complete a given task and doing high risk tasks.

A limitation of this study was its small sample size and its cross-sectional design. Despite assuring anonymity and confidentiality of their responses underreporting of diverse group of stressors might be an issue. However, our study was the first to describe stress been faced by postgraduate medical students in Pakistan. The major stressors that have been faced by the students were related to academic and performance pressure. Further studies must be carried out to identify the risk factors involved and its effects. Our use of valid stress scales increases the validity of our results and the generalizability of our results to other institutions in Pakistan.

\section{Conclusion}

From the above study, one can comprehensively conclude that postgraduate medical training is highly demanding in every aspect, requiring a 
student to be mentally and physically alert to handle the pressure. Of all the stressors, academic related stressors were found to have the greatest impact and intensity in both programs. By understanding this stressor, one can strive to lessen its adverse effect and the toll it takes on postgraduate students - thus better enabling them to handle the stress of postgraduate medical training. Levels of stress were found to be higher in clinical medicine followed by academic medicine.

It is recommended that these stressors should be addressed and managed using coping mechanisms. Counselling should also be made available to the students as an appropriate measure. Stress if unattended during this vital period of training can have detrimental effects on the quality of patient care on the part of the physician attending as well as those pursuing M. Phil or Ph. D. degrees in basic sciences.

\section{Reference}

1. Ramazn M, Riaz A. Recognition of stress and manifestation of stress among university teachers. IJCRB. 2013; 4 (9): 634-47.

2. CooperCL, Dewe PJ, Driscoll MY. Organizational Stress: A Review of Critique of Theory, Research and Application. $1^{\text {st }}$ ed. California: Sage Publications; 2002.

3. Hashmi F, Ahmad M. Stress Levels in Medical Residents of a Teaching University in the Province of Sindh, Pakistan: its effects on the Quality of Life of Residents. A.P.M.C. 2008; 2 (1): 41-5.

4. Stewart SM, Lam TH, Betson CL, Wong CM, Wong AM. A prospective analysis of stress and academic performance in the first two years of medical school. Med Educ. 1999; 33 (4): 243-250.

5. Rosenham DL, Seligman ME. Abnormal psychology. 2nd ed. New York: Norton; 1989.

6. Myers DG. Stress and Health. In: Exploring Psychology. 6th ed. New York: Worth Publishers, 2005.

7. Yusoff MSB, Rahim AFA, Yaacob MJ. The sensitivity, specificity and reliability of the Malay version 12-items General Health Questionnaire (GHQ-12) in detecting distressed medical students. Am J Psychiatry. 2010; 11(1): 1-8.
8. Kjeldstadli K, Tyssen R, Finset A, Hem E, Gude T, Gronvold NT, et al. Life satisfaction and residence in medical school - six year longitudinal, nationwide and comparative study. BMJ Med Educ. 2006;6:48.

9. Cohen JS, Patten S. Well-being in residency training: a survey examining resident physician satisfaction both within and outside of residency training and mental health in Alberta. BMC Med Educ. 2005; 5: 21.

10. Whitman NA. Student stress: effects and Solutions. (1985) Association for the study of higher education. ERIC Digest.Washington, DC. Available from: http://www.ericdigests.org/pre-926/stress.html

11. Yusoff MSB, Rahim AFA, Yaacob MJ. The development and validity of the Medical Student Stressor Questionnaire (MSSQ). Am J Psychiatry. 2010; 11 (1): 1-12.

12. Yusoff MSB. Personal and professional development for postgraduate: Exploring and managing stress. Malaysia: Pustaka Aman Press, 2009.

13. Khan SM, Sajid M, Areef B, Syed AU, Yasir $\mathrm{J}$. Prevalence of depression, anxiety and their associated factors among medical students in Karachi, Pakistan. J Pak Med Assoc. 2006; 56 (12):584-6.

14. Gazder DP, Ahmad F, Danish SH. Stressors, Coursework Stress and Coping Strategies among medical students in a private medical school of Karachi, Pakistan. Edu Med J. 2014; 6: 20-9.

15. Yusoff MSB, Rahim AFA. Prevalence \& sources of stress among postgraduate medical trainees: Initial findings. Am J Psychiatry. 2010; 11 (2): 1-10.

16. Garrud P. Counseling needs and experience of junior hospital doctors. BMJ. 1990; 300: 4457.

17. Stewart SM, Betson C, Marshal I, Wong CM, Lee PW, Lam TH. Stress and vulnerability in medical students. Med Educ. 1995; 29 (2): 119-27.

18. Gutherie EA, Black D, Shaw CM, Hamilton J, Creed FH, Tomenson B. Embarking upon a medical career. Psychological morbidity in first year medical students. Med Educ. 1995; 29 (5): 337-41.

19. Baldwin PJ, Dodd M, Wrate RM. Young doctor's health. Health and health behavior. Soc Sci Med. 1997; 45: 41-4.

20. Pino M, Lopez JJ. Stress and adjustment at the beginning of postgraduate medical training. Actas Luso Esp Neurol Psiquiatr Cienc Afines. 1995; 23 (5): 241-8.

21. Caplan RP. Stress, anxiety and depression in hospital consultants, general practitioners and 
senior health service managers. BMJ. 1994; 309: 1261-3.

22. Visser MRM, Smets EM, Oort FJ. Stress, satisfaction and burnout among Dutch medical specialists. CMAJ. 2003; 168 (3):271-5.

23. Collier VU, McCue JD, Markus A, Smith L. Stress in medical residency: status quo after a decade of reform? Ann Intern Med. 2002; 136 (5): 384-90.

24. Toews JA, Lockyer JM, Dobson DJ, Simpson E, Brownell AK, Brenneis F, et al. Analysis of stress levels among medical students, and graduate students at four Canadian schools of medicines. Acad Med. 1997; 72(11): 9971002.

25. Firth J. Levels and sources of stress in medical students. Br Med J. 1986; 292: 1177-80.

26. Ochsmann EB, Zier U, Drexler H, Schmid K. Well prepared for work? Junior doctors' selfassessment after medical education. BMC Med Edu. 2011; 11: 99.

27. Bansal RK, Pareshbhai B, Kalpesh J, Krunal G, Pushpendra H, Pawar AB, et al. Stress profile of Post graduate medical residents in Western India. National J Community Med. 2010;1: 55-6. 